\title{
Análisis armónico y rítmico del Piano II - Slow de la obra 2x5 de Steve Reich
}

\author{
Ana Luz Barraza Caballero \\ a.l.b.c90@gmail.com \\ Estudiante de la Licenciatura en Música
}

\section{Introducción}

Este trabajo de investigación se enfoca en el segundo movimiento (Slow) de la pieza $2 \times 5$ (2008) del compositor minimalista Steve Reich.

El objetivo es realizar un análisis formal del segundo movimiento de la pieza y descubrir los elementos musicales que hacen de la composición y el compositor característicos dentro de la corriente minimalista. Comenzamos por ubicar a la pieza en su contexto para abordar la problemática, después presentamos la metodología y por último analizamos armónica y rítmicamente el segundo movimiento de la pieza.

Una de las motivaciones principales para abordar la obra $2 \times 5$ es debido a que es una obra muy joven (ocho años) y hay muy poca investigación sobre ella.

\subsection{Problemática}

\subsection{Contexto Histórico}

Steve Reich (1936) es un compositor americano considerado uno de los pioneros en el género minimalista. El minimalismo converge en los años sesenta, siendo así clasificado dentro de la música contemporánea o música del siglo $\mathrm{XX}$ (Morgan, 1994).

La composición $2 \times 5$ (2008) muestra características que evidencian al compositor tanto en su estilo de composición como en su interés por experimentar con elementos que otros compositores no se atrevieron en su época.
Hay bastantes referencias (la mayoría audiovisual) sobre el compositor, e.j. Music for 18 musicians, Violin phase, Clapping music. Pero hay muy poca información tanto visual como escrita referente a la pieza $2 \times 5$. De esto último nace el interés por abordar esta pieza como objeto de estudio.

Son pocos los teóricos que han investigado sobre Steve Reich, como lo son Biareishyk, S., y su estudio sobre la pieza Come out del mismo compositor o Fink (2005) en su libro Repitiéndonos, en el cual estudia el género musical, los compositores icónicos ubicándolos dentro de un contexto social e histórico.

\subsection{Planteamiento de la problemática} ¿Cuáles son las características que definen a Slow de $2 \times 5$ como una pieza minimalista y no de algún genero popular?

\subsection{Metodología}

La metodología de este trabajo sigue la lógica del minimalismo, la cual se enfoca en los desfases que suceden después de la repetición de la misma melodía en diferentes tiempos y cambiando el sentido de la frase al dar acentos a diferentes notas de la frase durante estas repeticiones.

Las diferentes técnicas de investigación que se usarán para la realización de este proyecto son las siguientes:

- Investigación documental

- investigación auditiva o visual (análisis de fuentes de audio o video)

- Investigación participante (ejecución 
presentación del segundo movimiento de $2 \times 5)$.

\subsection{Objetivo General}

- Analizar armónica y rítmicamente el Piano II de Slow de la obra $2 \times 5$

\subsection{Objetivos Particulares}

- Destacar los elementos musicales característicos del minimalismo

- Destacar los elementos musicales particulares de Steve Reich a través de describir el movimiento de la línea armónica del Piano II en Slow y los desfases rítmicos que se generan en el Piano II durante el segundo movimiento de $2 \times 5$.

- Ejecutar la pieza para un mejor análisis de la misma.

\subsection{Justificación}

A partir de esta investigación entenderemos el porqué del uso y acompañamiento de instrumentos electrónicos, desfases rítmicos y repeticiones prolongadas en Slow de $2 \times 5$. A su vez, aportará conocimiento para la ejecución del mismo.

Me considero con el perfil adecuado para abordar el tema y generar nuevas aportaciones, que servirán a futuras investigaciones sobre el compositor Steve Reich, considerado uno de los más influyentes del siglo XXI. De la misma manera, espero contribuir con la investigación sobre la pieza $2 \times 5$, una de las más peculiares debido al uso de instrumentos electrónicos asociados al Rock y finalmente, es importante señalar que el minimalismo es un género poco estudiado en nuestro estado y país lo que me motiva para abordarlo.

\subsection{Metas}

La meta principal es generar criterios para la interpretación y análisis de este género tan subestimado por la mayoría de los músicos profesionales (esta última frase es meramente basada desde mi perspectiva).

\subsection{Análisis y discusión}

En este apartado elaboramos el análisis y se presentan los resultados.

\subsection{Análisis armónico}

La armonía durante Slow se desarrolla en cuatro casas tonales. Empieza el movimiento en Mi mayor con el IV grado seguido del $\mathrm{V}$ en el bajo, oscilando entre estos dos, para después presentar la tónica (en el mismo bajo), mientras que la mano derecha sólo toca un clúster de cinco notas dando la sensación de una tónica con pedal.

En el cuarto sistema sucede una mixtura, la primera modulación de Mi mayor a Mi menor, en la cual se repite el mismo diseño armónico a diferencia que el bajo sólo oscila entre el VI y VII grado de la escala natural de Mi menor.

En el octavo sistema encontramos la segunda modulación que ahora nos transporta a la tonalidad de Sol menor, en la cual la línea del bajo se mueve en el VI, VII, V y I grado. En la mano derecha hay más movimiento, siguen siendo clústeres, pero ya enfatizan a la nueva línea que el bajo está creando.

En el catorceavo sistema sucede la última modulación a partir del penúltimo compás, siendo ésta la última del movimiento y la que nos lleva a la tonalidad de Si menor. Es la más elaborada (armónicamente hablando), la línea del bajo se mueve en el VI, VII, I, III, V y IV grado, siguiendo el orden anterior. La mano derecha ya no genera clústeres, sino acordes que armonizan a la línea del bajo.

\subsection{Análisis rítmico}

Slow, como su nombre lo dice, es un movimiento lento, pero gradualmente en crecimiento y no necesariamente en la 
velocidad, si no en la factura rítmica. El movimiento está en un compás de 3/4 con un tempo de 86 bpm.

En los primeros trece compases la rítmica se presenta de la misma manera, acentuando cada golpe independientemente del pulso en el que caiga, engañándonos y haciéndonos sentir que estamos en un compás de 4/4.

Se observa que hasta el segundo cambio de modulación (explicado arriba) hay un cambio en la rítmica a figuras de menor tiempo, creando una sensación de mayor movimiento, aun así escuchando el 4/4.

En la última modulación es más notorio el cambio rítmico, ya que la rítmica de ésta es la más diferente a todas. A partir de este punto la rítmica se vuelve muy importante ya que se genera la mayor sensación de desfases en los instrumentos, cada uno entrando una corchea después (no todos al mismo tiempo) de lo que hace el Piano II.

\section{Conclusiones}

$2 \times 5$ es el ejemplo claro del minimalismo, con un toque de música popular como el Rock y la electrónica, por el uso de guitarras y bajo eléctrico, así como el uso de los casetes como elemento para secuenciar el desfase, una técnica elaborada y desarrollada por Steve Reich desde los inicios de su carrera musical.

Se entiende por desfase como el atraso o la entrada tardía de uno, dos o más elementos con pulsos diferentes, pero coincidiendo siempre en algún punto: un ejemplo sería comenzar a ver dos estrellas pulsar al mismo tiempo sólo que una está ligeramente atrasada debido a que pulsa a mayor velocidad, para luego generar una sensación de adelanto, hasta llegar al punto inicial coincidiendo de nuevo con la otra estrella, llenando el espacio y tiempo creado por este hermoso efecto.

Con esto llegamos a la conclusión que Slow de $2 \times 5$ está repleto de estos desfases, generando la sensación de que tras varias repeticiones se presenta un nuevo tema, pero simplemente es el mismo paseándose por nuestra cabeza como una imagen auditiva del sonido en estéreo hasta llegar al unísono (Reich, 2016).

\section{Bibliografía}

Agency Rayfield Allied. (2016). Steve Reich. Recuperado de Internet, abril de 2016. http://:www.rayfieldallied.com.

Biareishyk, S. (2012) Come Out to Show the Split Subject: Steve Reich, Whiteness, and the Avant-Garde. Current Musicology, 93, pp. 73-93)

Morgan, R.P.(1994). La música del siglo XX. Madrid: Akal

\section{Material audiovisual}

Steve Reich. (2009). Phase to Face. Euro Arts.

Reich on Reich, Boosey \& Hawkes. (2011).

Steve Reich - Rhythm and minimalism. (2012). The Music Show, ABC Radio National 


\section{IMÁGENES}

Nenúfares
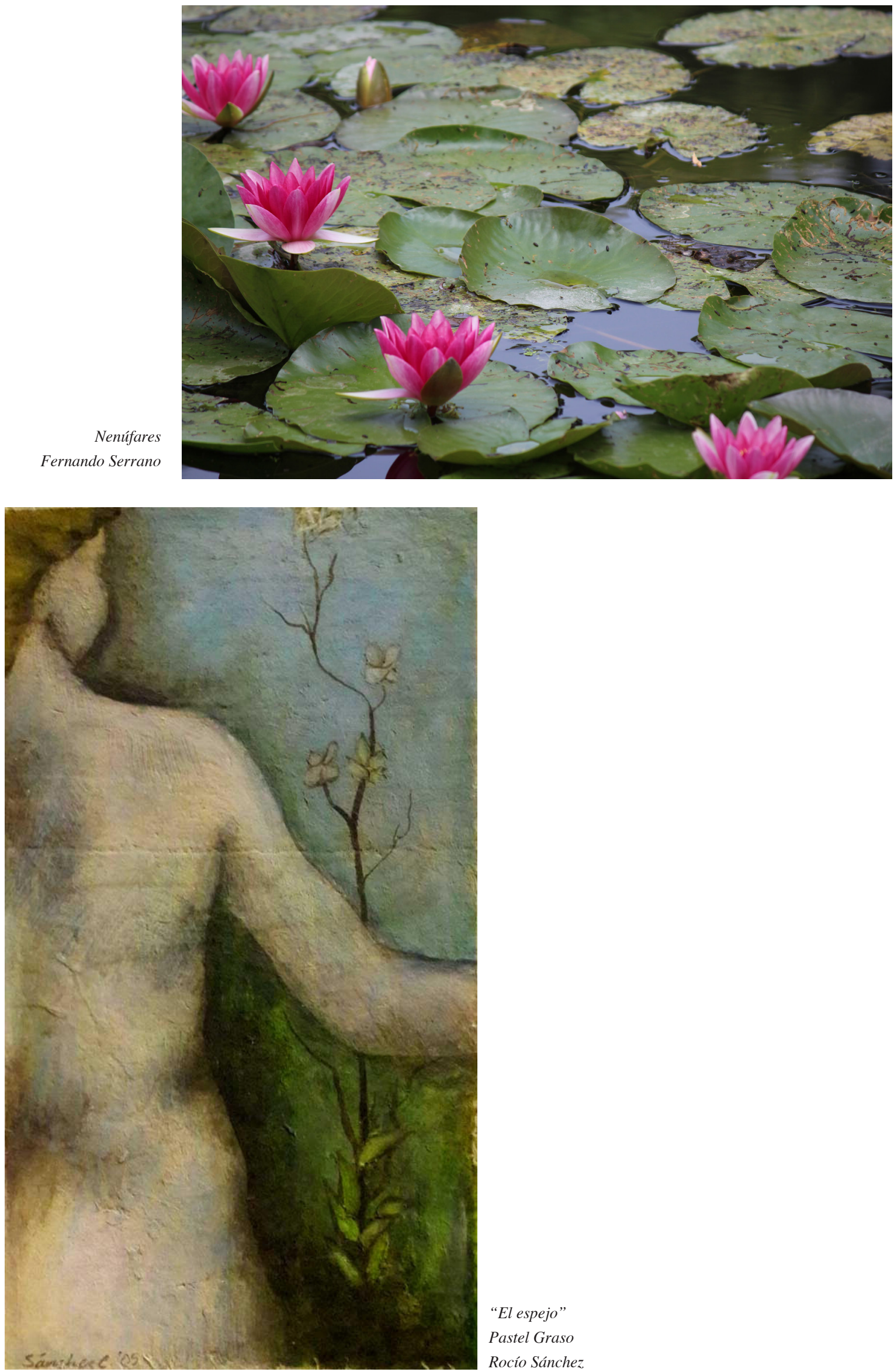